\title{
RESISTENCIA POLÍTICA Y CREACIÓN LITERARIA EN GUINEA ECUATORIAL
}

\author{
POR \\ JoSEPH-DÉSIRÉ OTABELA \\ University of Missouri-Columbia
}

Cada obra literaria, observa el escritor guineano Justo Bolekia, "es producida según las circunstancias, el conocimiento y el momento histórico del autor" ("Rasgos" 53). De manera que la creación literaria y cultural debe entenderse y analizarse en el contexto amplio de la vida histórica y social de los pueblos. El contexto político constituye, desde esta perspectiva, el terreno inmediato sobre el cual se llevan las luchas que redundarán en la creación y en el desarrollo de los pueblos y de su producción cultural. El objetivo principal del escritor comprometido es incidir ideológica y políticamente en la transformación de su sociedad. De manera que la obra de cada escritor encierra, de alguna manera, su versión de la realidad y una reflexión moral sobre la Historia y el entorno histórico en el que el autor ha vivido y evolucionado, como persona y como escritor. Aplicando estas categorías indicadas por Justo Bolekia a Guinea Ecuatorial, vamos a identificar tres momentos que marcan la historia política del país, y así enfocar nuestro ensayo en la época colonial, la dictadura de Francisco Macías y, desde luego, la pos-independencia.

\section{Contexto}

En Guinea Ecuatorial la producción literaria y artística se ha ido construyendo poco a poco en medio de un panorama político brutalmente desolador en el interior del país, un panorama poco o nada favorable a la eclosión de una cultura nacional. Conviene puntualizar que lo que en realidad constituye la nación guineana es un mosaico de etnias y tribus que conviven en un territorio compuesto por una parte continental, el Río Muni, una isla mayor, el Bioko y unos islotes que forman la provincia de Annobón; los principales grupos étnicos son los Fangs, los Bubis, los Combes, los Annoboneses y los Ndowes, siendo los Fangs el grupo mayoritario.

Durante el colonialismo, Guinea Ecuatorial fue constantemente sometida a lo que Gustau Nerín considera como un "bombardeo permanente de discursos incuestionables y adhesiones incondicionales" (121), pues al autoritarismo colonial pronto se sumaron 
unas prácticas totalitarias propias del franquismo, con la lógica consecuencia de la imposibilidad de todo debate social o cultural. No mejoróla situación con la independencia, pues notables intelectuales guineanos tuvieron que salir precipitadamente del país como consecuencia directa de la dureza de la tiranía de Macías Nguema. En la actualidad, hay un profundo lamento frente al desengaño por el fracaso que va de la independencia política de finales de los años sesenta hasta el proceso democrático doloroso e inacabado actual. ¿Cómo se manifiestan todas estas circunstancias en la literatura de Guinea Ecuatorial? ¿Cuál es la visión, o mejor dicho, la perspectiva del escritor guineano?

\section{II. ¿REIVINDICACIÓN IDENTITARIA O CONSENTISMO?}

Es evidente el compromiso político y social manifestado por los literatos guineanos en sus obras, a pesar de la diferencia de criterio observada entre las diferentes generaciones que componen el panorama literario de Guinea Ecuatorial. Durante la colonización española marcada en su último tramo por la dictadura franquista en la metrópoli, la mayoría de los intelectuales guineanos inician sus primeros pasos como escritores redactando artículos etnográficos en las revistas misioneras coloniales. ${ }^{1}$ Los pioneros de la literatura guineana escrita, Leoncio Evita y Daniel Jones en sus respectivas novelas Cuando los combes luchaban (1953) y Una lanza por el boabi (1962) tratan de dar a conocer a sus lectores la realidad de sus respectivos pueblos durante la colonización española.

Narrada en tercera persona a cargo de un narrador heterodiegético, la obra de Leoncio Evita describe no sólo las costumbres y los ritos practicados en la Guinea profunda, en este caso los pueblos de la etnia Combe, la del autor, sino también las peripecias a las que se enfrentan los múltiples personajes de la obra en su desesperado intento de acabar con la secta bwiti que siembra el terror y el hambre en los pueblos de Ndyebengo y Bolondo. Por su parte, Una lanza por el boabí, cuyo paralelismo con la mencionada novela de Leoncio Evita es evidente según una evaluación de Antonio Carrasco González, ${ }^{2}$ narra las vicisitudes y preocupaciones de una familia de indígenas guineanos, liderada por Maximiliano Jones, un reyezuelo local de considerable importancia en los últimos años de la dominación española en los alrededores de San Carlos (actual Luba).

Si a partir de la descripción y de la presentación de los ritos tradicionales que informan sobre la riqueza cultural del país, es innegable el aporte considerable de estas

1 Fue el 10 de enero de 1947, en el número 1236, cuando se publican por primera vez contribuciones de autores guineanos en la revista misionera La Guinea española, en un apartado titulado "Historias y cuentos".

2 Carrasco González afirma que Cuando los combes luchaban, la novela de Leoncio Evita "tiene ciertos paralelismos con la novela de Jones, en la que también se narran las preocupaciones ordinarias de una familia indígena en los albores del siglo xx" (248).

Revista Iberoamericana, Vol. LXXX, Núms. 248-249, Julio-Diciembre 2014, 883-898 
obras pioneras en la reivindicación de la cultura de las respectivas tribus de sus autores, no deja de ser cierto que dichos textos sirvieron como un importante instrumento propagandístico para la administración colonial española. Mbare Ngom observa por ejemplo que Cuando los combes luchaban "no sólo defiende la necesidad del hecho colonial, sino que lo justifica. Asimismo, se encuadra dentro de la llamada 'literatura de consentismo' ("La literatura” 412). Una opinión ratificada por Donato Ndongo cuando habla de Una lanza por el boabí como una novela que "trata de la situación colonial que aparece bajo una luz muy favorable, al tiempo que el narrador pasea una mirada muy crítica sobre las costumbres y los rituales de los grupos indígenas de la isla de Fernando Poo" (Ndongo y Ngom 20). En reacción a esta postura de Mbare Ngom y de Donato Ndongo, Benita Sampedro Vizcaya afirma que "tienen su espacio en estos anaqueles de la ravisión colonial novelas escritas por autores guineanos durante la ocupación misma, y publicdas incluso bajo la mirada atenta y el control narrativo [...] de las autoridades metropolitanas como Una lanza por el boabi de Daniel Jones Mathama, o Cuando los combes luchaban de Leoncio Evita" (12); considerando así las categorizaciones de Donato Ndongo y de Mbare Ngom “dañinamente reduccionistas y miopes”. En su argumento, Sampedro ratifica asimismo el análisis de Adam Lifshey quien propusiera que "categorizing Cuando los combes luchaban as a collaborationist text is one of two ways that scholars have sought to exorcise its hauntings of empire." Sin embargo, tenemos que en estas novelas pioneras de la literatura nacional, no era sorprendente ver a los personajes en una actitud de flagrante admiración por la colonización española y sus actores; en la novela de Evita por ejemplo, el rey Roku, que se ha asimilado a la presencia del colono español, reniega abiertamente de prácticas tradicionales africanas, incluidas las ceremonias religiosas, porque "a pesar de que era salvaje, despreciaba las creencias del país [...] La llegada del equipo evangelista protestante le apartó todavía más del común sentir de los hombres de su raza. Ya no veneraba a los curanderos y mucho menos los ensalmos de éstos" (43).

Lo que hay que reconocer es que la voluntad de reivindicación de la cultura nacional, innegable en estas novelas, queda sin embargo diluida o sofocada por un control casi inquisitorial, una censura ejercida por el estamento cultural español, al que había que someter los textos antes de su publicación; ${ }^{3}$ en estas condiciones, toda opinión contraria

\footnotetext{
3 Evidencia de su papel de censor la tenemos en estas palabras de Carlos González Echegaray en el prólogo de la primera edición de Cuando los combes luchaban: "No le di (a Leoncio Evita) palabra de escribírselo hasta que no me convenciera de que se trataba de algo distinto de los relatos inconexos y absurdos que algunos morenos seudo-intelectuales escriben [...] Pero mi sorpresa fue en aumento a medida que iba leyendo, al encontrarme con una obrita francamente aceptable, y que bien pudiera haber sido escrita por cualquier escritor novel nacido en nuestra Patria" (11). Estas palabras delatan cierto desprecio hacia los escritores e intelectuales de raza negra, considerados incapaces de un razonamiento coherente y lógico, unas palabras que traducen la ideología y la doctrina del colonizador que considera que la actividad literara sólo es propiedad de los europeos, de los occidentales.
}

Revista Iberoamericana, Vol. LXXX, Núms. 248-249, Julio-Diciembre 2014, 883-898 
a la ideología del colonizador corría el riesgo de ser censurada, al mismo tiempo que toda reivindicación o afirmación de la cultura tradicional frente a la "poderosa" cultura del "maestro" quedaba nula. En el prólogo a la segunda edición de Cuando los combes luchaban, Carlos González Echegaray desvela la verdadera intención primera del colono en el momento de la publicación de la novela de Leoncio Evita:

Es curioso comprobar cómo una iniciativa que resultaba políticamente rentable para la administración colonial española, al presentar el resultado positivo de una estructura educacional [...] al mismo tiempo paradójicamente venía a desterrar la idea de un africano atrasado e imposible de integrar plenamente en la cultura europea. (Evita 14)

Esta tendencia se va diluyendo progresivamente para dar paso a una generación de escritores en cuyas plumas se desarrolla un cierto renuevo literario a través de un enfoque de reivindicación ideológica correspondiente a los años de la dictadura oncenal de Macías.

\section{REAPROPIACIÓN DE LA MEMORIA HISTÓRICA}

Antecedentes políticos, entre otros, justifican la publicación de Antología de la literatura guineana (1984) de Donato Ndongo, el texto revelador de una literatura escrita en Guinea Ecuatorial. En la introducción, el autor aclara que "una obra literaria no es una fotografía, una mera trascripción de la realidad, y si fuera sólo eso perdería su función utópica, de anticipación, puesto que existe una relación entre la obra y las necesidades colectivas del grupo social del que proviene la obra" (13).

Para recaudar fondos para uno de los movimientos políticos de la resistencia antimaciísta en Madrid, Donato Ndongo y Francisco Zamora editan en 1977 Nueva narrativa guineana y Poetas guineanos en el exilio; son dos opúsculos que recogen en gran medida textos inéditos de ambos amigos y que serán más tarde el fundamento de la primera antología de Donato Ndongo. Junto con Historia y tragedia de Guinea Ecuatorial del propio Donato Ndongo, estos textos pueden verse como una iniciativa de re-apropiarse de una historia y de una literatura guineanas; una historia y una literatura que, hasta entonces, habían sido escritas, contextualizadas y analizadas, es decir, controladas exclusivamente desde la perspectiva del colonizador, con el evidente riesgo de omisión o de falsificación de "ciertas verdades" (Bolekia, Aproximación 10) sobre lo realmente acontecido durante la colonización española; ${ }^{4}$ una manera de reencontrarse

4 De hecho, Donato Ndongo reconoce que Historia y tragedia de Guinea Ecuatorial fue escrita para llenar un vacío, para devolver a los guineanos su "verdadera historia" (Otabela y Onomo 106), considerando de esta manera los libros publicados hasta entonces por los historiadores españoles u occidentales

Revista Iberoamericana, Vol. LXXX, Núms. 248-249, Julio-Diciembre 2014, 883-898 
con su historia, con sus raíces. Al mismo tiempo, se trataba de reunir, desde el exilio, a los intelectuales y profesionales guineanos en torno a un doble combate político y cultural contra la dictadura de Francisco Macías que acababa de tomar las riendas del poder político tras la salida de los agentes del sistema colonial español en 1968.

La dictadura de Francisco Macías (1968-1979) es, sin lugar a dudas, el acontecimiento político de mayor trascendencia de la Guinea Ecuatorial posindependentista; es también uno de los dramas más silenciados de este país. Los escritores guineanos que más desarrollaron el tema de la dictadura y sus consecuencias son precisamente los de la segunda generación, llamados muy a propósito por diversos nombres que informan sobre las dificultades a las que hicieron frente para desarrollar su labor artística: unos la llaman "generación perdida"; otros la señalan como la generación de "los años del silencio"; 5 otros en fin, como José Fernando Siale, la designan como la generación de la "reivindicación ideológica". ${ }^{6}$ Una generación que Michael Ugarte cataloga como "The Macías Generation", cuyas obras son, según el crítico estadounidense, "expressions of political dissidence as well as instropections of their own otherness not only in Spain but also in relation to a political system they abhor" (xiii).

La característica esencial común a los escritores de este grupo es que casi todos sufrieron directa o indirectamente los efectos nefastos de la tiranía de Macías, obligados, muchos de ellos, por circunstancias obvias, a vivir y a ejercer su actividad lejos de su Guinea, o sea en el exilio. ${ }^{7}$ Lógicamente, muchos se convirtieron en su tierra de acogida

como una falsificación de la historia de Guinea Ecuatorial. A raíz de Donato Ndongo, otros escritores guineanos documentaron la historia de su país; podemos mencionar a Justo Bolekia en Aproximación a la historia de Guinea Ecuatorial (2003), Fernando Muakuku Rondo Igambo en Guinea Ecuatorial. De la esclavitud colonial a la dictadura nguemista (2000) o Juan Balboa Boneke y Fermín Nguema Esono en La transición de Guinea Ecuatorial. Historia de un fracaso (1996).

5 La "Generación perdida" es el nombre con el que el poeta, ensayista y novelista Juan Balboa Boneke designa a aquellos escritores guineanos que no tuvieron el tiempo y los medios suficientes para expresarse entre 1968 y 1979, amordazados por la dictadura de Francisco Macías. Donato Ndongo, quien prefiere hablar de la generación de "los años del silencio" agrupa bajo esta apelación los que habían empezado a escribir en los años 50 y 60, que con la independencia fueron obligados a dejar de escribir como consecuencia de la vorágine represora que se apoderó del país durante la presidencia de Francisco Macías.

6 José Fernando Siale hizo esta declaración en una conferencia pronunciada en la Universidad de MissouriColumbia, el 30 de marzo de 2009. El título de su conferencia era "Escritores guineanos y expresión literaria".

7 Un ejemplo concreto es Joaquín Mbomio, el autor de El párroco de Niefang y de Huellas bajo tierra, del que dicen Donato Ndongo y Mbare Ngom que "sufrió en carne propia la persecuión nguemista durante la dictadura de Francisco Macías. El 24 de marzo de 1978, fue detenido por la policía política y acusado de alta traición [...] ingresó en la Cárcel Modelo de Bata. Luego fue condenado a trabajos forzados en las plantaciones de cacao de la isla de Bioko" (456). Sus dos novelas son una exposición pública de la tragedia de Guinea Ecuatorial durante la colonización española y sobre todo durante la dictadura de Macías Nguema.

Revista Iberoamericana, Vol. LXXX, Núms. 248-249, Julio-Diciembre 2014, 883-898 
en militantes y activistas de los movimientos revolucionarios de resistencia antimaciísta; lo cual justifica la temática antidictatorial o revolucionaria que atraviesa su obra.

Desde "Vamos a matar al tirano", el poema de Francisco Zamora, en cuya última estrofa podemos leer:

\author{
Madre \\ dame esa lanza \\ esa vieja lanza \\ y ya no habrá más tiranos \\ nunca más dictadores \\ sobre mi pueblo, sobre tu miseria \\ sobre tu miedo (Ndongo, Antología 43)
}

hasta el poema "Añoranza" o el ensayo ¿Dónde estás guinea? ${ }^{9}$ Ambos textos de Juan Balboa Boneke, pasando por "El silencio de la nostalgia" o "La voz de los oprimidos", dos poemas de Anacleto Oló Mibuy, ${ }^{10}$ los escritores de esta generación tratan de transmitir a sus lectores sus más profundos sentimientos, o sea su dolor y su tristeza, al mismo tiempo que desvelan al mundo la tremenda situación atravesada por el pueblo guineano, una situación expresamente silenciada por la España franquista bajo el "paraguas" de la "materia reservada". "En su poemario Memoria de laberintos, Francisco Zamora dedica el poema "Reservada materia" a este silencio oficial decretado por el Gobierno de Francisco Franco sobre el tema de Guinea, lo que el poeta Justo Bolekia denomina "la época del mutis" (Bolekia, "Rasgos" 53). En los útimos versos del poema de Zamora,

8 En el poema "Añoranza", por ejemplo, además de añorar el pasado colonial (pese a la explotación que ello supuso para los guineanos) de su país que asimila con la libertad, el poeta también plantea la problemática del futuro incierto de Guinea y de sus habitantes. Sin embargo, versos como "mi ayer", o "quisiera ser de nuevo niño" y "con los pies desnudos" bien pueden identificarse con el discurso colonial que siempre ha considerado a los africanos como unos niños, unos salvajes con los "pies desnudos", a los que había que subvertir, evangelizar, educar y pulir para convertirlos en "buenos negros".

9 ¿Dónde estás Guinea? (1978) hace un repaso de la realidad socio-histórica y política del proceso que llevó al advenimiento de la dictadura de Francisco Macías. El libro es también una reflexión sobre el nguemismo y sus consecuencias sobre la decadencia de la identidad del ser guineano y de su realidad. Juan Balboa aboga por la reconciliación como primer paso hacia la construcción de un proyecto nacional común y plural.

${ }^{10}$ Los mencionados poemas de Anacleto Oló, escritos durante el último tramo de la dictadura de Macías, sólo fueron publicados por primera vez en Antología de la literatura guineana de Donato Ndongo en 1984.

11 En 1971, el Gobierno español del general Francisco Franco declaró “materia reservada” toda información, comentario o noticia relacionada con Guinea Ecuatorial, lo que permitió al dictador guineano oprimir a su pueblo sin temor a ser denunciado por muchos guineanos que se encontraban exiliados en España. Sobre este tema, se puede leer a Rafael Fernández, Guinea, materia reservada.

Revista Iberoamericana, Vol. LXXX, Núms. 248-249, Julio-Diciembre 2014, 883-898 
se puede leer: "cuando la vida queda a merced de un pacto / un decreto / o el silencio, simplemente" (Zamora 38). El tono de las obras que entonces se publican desde el exilio de sus autores varía entre lo rabiosamente tremendista como por ejemplo en Donato Ndongo y lo que Juan Balboa Boneke llama un "aldabonazo suave" (Onomo y Otabela 35) contra la dictadura de Macías.

En el ensayo Historia y tragedia de Guinea Ecuatorial (1977) y sobre todo en la novela Los poderes de la tempestad publicada en 1997, es decir dieciocho años después de la caída del tirano, Donato Ndongo pone a la luz pública el horror de la Guinea de Macías; si en el ensayo, el escritor aporta informaciones documentadas sobre la colonización española y la mencionada dictadura, en la novela, describe el calvario de un abogado guineano que decide volver a su país para encontrarse inmerso en un mundo espeluznante. Para colmo de su desgracia, el protagonista, que nunca tomó en cuenta las serias advertencias de su amigo Miguel Nzamío - ¿¿no sabes que Guinea es hoy un país de muerte al que no se puede ir?" (Los poderes 13)- es detenido, encarcelado, torturado durante varios días, obligado a firmar una confesión y, finalmente, condenado sin juicio:

Elmiliciano esmirriado pero de brazo tan potente te pegó otro tremendo bofetón, que cogió de nuevo la parte superior de la mejilla y el ojo derechos [... Ibas a restregarte la parte dañada cuando arreciaron los golpes sobre ti, no eran selectivos, sino indiscriminados, en la cabeza, en la cara, en el pecho en el estómago, en los riñones [...] Una de las patadas propinadas por las recias botas militares del miliciano dejó un profundo vacío en tu bajo vientre, y se escapó toda tu fuerza. (Los poderes 247-48)

Escribir esta novela - confiesa el propio autor- fue un ejercicio de catarsis personal que le permitió ahogar toda la angustia, la rabia y la frustración acumulados durante su estancia de diez años en Guinea Ecuatorial entre 1985 y 1995, a raíz del Golpe de Libertad con el que Teodoro Obiang derrocó a su tío Macías en 1979. Donato Ndongo declara, en efecto, que "fue un buen ejercicio de auto-psiquiatría, un ejercicio terapéutico que me liberó de la locura" (Otabela y Onomo 114). Joaquín Mbomio presentó Los poderes de la tempestad como "un inmenso tabloide de horror, una secuencia vivencial drástica de nuestra propia existencia, una amarga pesadilla que nos deja sin sueño y en medio de una interminable noche en la oscura selva, sin luz ni lectura" (Mbomio, "El jeringazo" 48); una situación dramática que se identifica con el principio de lo que se denominó en su momento como el afro-pesimismo que Mbare Ngom caracteriza como:

un período de la historia de África marcado, por un lado, por la consolidación del poder personal abusivo e intolerante y el 'reinado' exclusivo del partido único; y por el otro, por la exclusión y empobrecimiento institucional de grandes sectores de la población. Y todo

Revista Iberoamericana, Vol. LXXX, Núms. 248-249, Julio-Diciembre 2014, 883-898 
ello en detrimento de un proyecto nacional político, social y económico enfocado hacia el desarrollo y el bienestar de la sociedad en general. (Ngom, "La autobiografía" 71) ${ }^{12}$

Durante casi once años, el régimen de Francisco Macías se dedicó a la persecución y eliminación sistemática de los intelectuales (maestros, profesores y trabajadores de la cultura) y opositores, creando un espacio determinado por lo que el escritor Kenyata gugi Wa Thiong'o describe como "The Culture of Silence and Fear" (38). Guinea Ecuatorial se convirtió en lo que Mbare Ngom llama un "gulag africano" ("Literatura" 122), ${ }^{13}$ realidad que describe el narrador en la novela El párroco de Niefang (1996), de Joaquín Mbomio Bacheng:

Salir con una barca a alta mar era considerado por el régimen de Macías como un acto de subversión que atentaba contra la seguridad del Estado. Por eso se mandó destruir todas las embarcaciones desde Mbonda hasta Río Campo, y desde Cuche hasta Corisco. Nada podía navegar. Se prohibía a toda la población del Litoral el acceso a su propio espacio marítimo. (37)

Además de Donato Ndongo y de Joaquín Mbomío en la novela El párroco de Niefang, Justo Bolekia en su ensayo Aproximación a la historia de Guinea Ecuatorial también expuso públicamente la tragedia de Guinea Ecuatorial. El libro de Justo Bolekia cuyo uno de los propósitos es revelar "ciertas verdades" omitidas en los libros publicados anteriormente por los colonizadores, quiere "contribuir a la recuperación mental de Guinea Ecuatorial ya no como colonia, sino como un país independiente con el que España y los Españoles mantienen estrechos lazos" (Bolekia, Aproximación 9).

El filósofo Eugenio Nkogo Ondó en El problema humano (1985), una colección de 23 ensayos escritos entre 1973 y 1977, recoge la experiencia traumática y dramática del exilio y de los problemas de la diáspora, extendiéndose a toda la realidad del África

${ }_{12}$ Conviene precisar que la situación descrita por Mbare Ngom, característica del afro-pesimismo no ha variado mucho, pese a disponer el continente africano de muchos recursos naturales y minerales; la democracia sigue siendo un sueño, a pesar de la presencia en muchos países de varios partidos políticos; se han reforzado los regímenes autocráticos caracterizados por los fraudes en las elecciones y los cambios repetitivos de las constituciones para mantener "ad vitam aeternam" en el poder a los actuales autócratas; hay violaciones constantes de los derechos humanos y de las libertades individuales; la pobreza y la miseria siguen siendo presentes en la gran mayoría de la población; no hay desarrollo ni político, ni económico, ni social.

13 Mbare Ngom toma esta expresión del artículo "Guinea Ecuatorial, el gulag africano" de M. Djibril publicado en la revista misionera Mundo Negro (31-32). Según la definición que proporciona Wikipedia, el gulag designa la Dirección General de Campos de Trabajo, una rama del Comisionado del pueblo para los asuntos internos que dirigía el sistema penal de campos de trabajos forzados y otras muchas funciones de policía en la extinta Unión Soviética. Algunos autores se refieren a todas las prisiones y campos de concentración de la historia soviética (1917-1991) como los Gulags.

Revista Iberoamericana, Vol. LXXX, Núms. 248-249, Julio-Diciembre 2014, 883-898 
subsahariana poco después de las colonizaciones europeas, a partir de la tragedia de otros exiliados africanos cuyas circunstancias eran parecidas a las de los guineanos. $\mathrm{Su}$ obra, ${ }^{14}$ enfocada esencialmente en el tema del existencialismo, queda lamentablemente poco difundida, principalmente a causa del desinterés manifestado por las editoriales, lo cual justifica la presentación que hace Michael Ugarte del filósofo guineano como "a concrete manifestation of Spanish deaf ears" (158).

Ekomo de María Nsue Angüe narra la historia de una mujer fang que, a la muerte de su marido, se atreve a cuestionar y romper ciertos tabúes de una sociedad africana rabiosamente anclada en el patriarcado. La novela plantea el enfrentamiento entre dos visiones de África: la primera, enraizada en sus tradiciones y la segunda que aspira a abrirse un poco más a la modernidad occidental, todo ello bajo las premisas de un latente conflicto de generaciones. Un planteamiento que permite a la autora abrir una reflexión sobre la situación de la mujer en un contexto tradicionalista a partir de la perspectiva de Ekomo, el personaje masculino y protagonista del relato, lo que, como observa Mbaré Ngom "confiere cierta legitimidad del discurso femenino de María Nsue" ("Literatura" 127). Es una novela que, como señala María Zielina, tiene como objetivo "descolonizar la mente de sus lectores a través del uso deliberado de la oralidad, y al mismo tiempo conservar la estética africana. Pero María Nsue va aún más allá, pues con Ekomo está dispuesta no sólo a descolonizar sino a 'de-patriarcalizar' la escritura e incursionar en la épica, en la novela de iniciación” (93). Por su parte, Michael Ugarte propone una lectura de la novela de María Nsue desde la perspectiva del retorno a África (xiv), un retorno que cuestiona el exilio y la emigración en el caso de la mujer africana.

La caída de Macías - derrocado por su sobrino Teodoro Obiang el 3 de agosto de 1979 en lo que él mismo llamó "golpe de libertad"- supuso una aparente "tregua" entre los escritores guineanos y las nuevas autoridades políticas de su país. Incluso muchos de ellos acudieron al llamamiento del nuevo mandatario para contribuir a la reconstrucción del país, en un intento de reconciliación con los guineanos exiliados. Como consecuencia directa, la unidad hasta entonces observada entre los escritores de la generación de "los años del silencio" conoce una cierta ruptura con la llegada de Obiang al poder: unos deciden apoyar al nuevo mandatario al tiempo que otros mantienen sino su oposición abierta, por lo menos su recelo ${ }^{15}$ a las declaraciones de

14 Entre sus obras podemos destacar El aspecto ético y social del existencialismo (1982); El método filosófico de Jean-Paul Sastre (1983); El problema humano (1985); Sobre la ruinas de la república de Ghana (1988); La trascendencia en la noche oscura (1989); La relación yo-mundo en Jean Paul Sartre (1990); La Pensée radicale (2005); Síntesis sintemática de la filosofía africana (2009).

15 Entre los recelosos, está Donato Ndongo quien, a pesar de regresar a Guinea Ecuatorial como muchos intelectuales exiliados, nunca ofreció su colaboración directa al gobierno de Obiang. Durante casi una década de estancia en su país, trabajó, primero, como director adjunto del Centro Cultural HispanoGuineano de Malabo y luego como delegado de la agencia española de noticias EFE para África Central.

Revista Iberoamericana, Vol. LXXX, Núms. 248-249, Julio-Diciembre 2014, 883-898 
"buenas intenciones" del presidente. Pero la tregua sólo dura unos diez años, el tiempo suficiente para darse cuenta de las muy pocas diferencias entre la primera y la segunda dictadura; las mentiras del régimen de Obiang, observa Donato Ndongo, "hacían ver el contraste entre los bonitos discursos y la realidad tan miserable, una miseria tanto material como espiritual, de tal manera que la mentira se había convertido en una forma de gobernar, en la norma, y la verdad en la excepción" (Otabela y Onomo 113-14). Juan Balboa Boneke, que había ocupado dos carteras ${ }^{16}$ en el gobierno, dimite, huye de Guinea y rompe "la tregua" en La transición de Guinea Ecuatorial. Historia de un fracaso, un ensayo en el que comparte autoría con el abogado Fermín Nguema Esono. El ensayo valora como un fracaso la colonización española y las dos dictaduras "nguemistas", la de Macías y la de Obiang.

\section{ASUMIR LA HERENCIA}

Uno de los problemas heredados de la dictadura de Macías y al que Teodoro Obiang no ha sabido aportar ninguna solución adecuada es el relacionado con las minorías étnicas, un tema desarrollado por poetas y ensayistas como Emiliano Buale Borikó, Muakuku Rondo Igambo o Justo Bolekia, uno de los escritores más críticos con la obra del actual mandatario guineano. Destacado miembro del Movimiento para la Autodeterminación de la Isla de Bioko, un movimiento bubi de oposición a la política de Obiang, Justo Bolekia observa en una conversación que tuvimos con él que en cuarenta años de independencia de su país, los proyectos gubernamentales nunca han contemplado ni salvaguardado la configuración cultural de las etnias de Guinea Ecuatorial; ${ }^{17}$ lo cual ha provocado una exclusión identitaria de gran parte de la población guineana hasta el punto de no sentirse implicados en el proyecto político del mandatario guineano. Razón por la cual los productores culturales y literarios se han apropiado del discurso identitario con el propósito de buscar la inclusión de todos los habitantes de Guinea Ecuatorial y promover espacios de convivencia y de reconocimiento con símbolos culturales compartidos. Ensayos como Curso de lengua bubi (1991), Antroponimia bubi. Estudio

16 El escritor regresa a Guinea en 1984, acudiendo al llamado de Obiang para contribuir a la obra de reconstrucción del país. Inmediatamente es nombrado Consejero Presidencial en materia de Cultura. A principios de los años 90, asciende a Ministro de Trabajo y Asuntos Sociales y, en 1992, pasa a ocupar la cartera de Cultura, Turismo y Promoción Artesanal. Su distanciamiento con el régimen tras su cese en 1994 le obliga a tomar nuevamente la "senda tortuosa del exilio", a pesar de haber afirmado a través del protagonista de su novela que nunca más volvería a exiliarse (Balboa Boneke). Desde entonces, Balboa Boneke observa un implacable y enigmático silencio desde su nuevo exilio español.

17 Las principales etnias de Guinea Ecuatorial son los Fang, los Bubis, los Combes, los Annoboneses y los Ndowes, siendo los Fang el grupo mayoritario al que perteneció Francisco Macías, el primer presidente y al que pertenece Teodoro Obiang, el presidente actual. De hecho, los cargos más importantes en el Gobierno, en el ejército y en las empresas estatales están entre las manos de los Fang.

Revista Iberoamericana, Vol. LXXX, Núms. 248-249, Julio-Diciembre 2014, 883-898 
lingüistico (1994), Narraciones bubis. Otra morfología del cuento africano (1994) o los poemarios Löbëla (1999), Ombligos y raices (2006) y Las reposadas imágenes de antaño (2008), todos de Justo Bolekia, cumplen con este cometido de reivindicación del espacio de la comunidad bubi dentro del gran espacio que es Guinea Ecuatorial, al lado de otros nacionalismos como el fang, el annobonés o el Ndowe, como bien demuestran los textos reunidos en el ensayo Conflictos étnicos y gobernabilidad: Guinea Ecuatorial (2006) de Muakuku Rondo Igambo. ${ }^{18}$

Otro desacuerdo entre los políticos guineanos y sus intelectuales está relacionado con la decisión de los primeros de ingresar el país en la Organización Internacional de la Francofonía en 1985, cuya consecuencia directa fue la adopción del francés como segunda lengua oficial del país, al lado del ya existente español, una opción que entraba en clara contradicción con las resoluciones del Primer Congreso Internacional Hispano Africano de Cultura celebrado en Bata en 1980. ${ }^{19}$

Francia, cuya presencia en Guinea se remonta mucho antes de la Conferencia de Berlín, cuando trató de invalidar el Tratado de Ildefonso (1777) entre España y Portugal, nunca ocultó sus intenciones de arrebatarle a España su única posesión en África subsahariana. Con la independencia del país y sobre todo la caída de la tiranía de Macías - muy inclinado hacia los países del bloque comunista que le daban su apoyo- reaparece el fantasma de la rivalidad entre España y Francia sobre el control de la antigua colonia española. Teodoro Obiang, cuyas relaciones con la antigua potencia colonizadora no son muy buenas, encuentra en París un apoyo inesperado; por su lado, París ve en la ocupación de Guinea la posibilidad de realizar su anhelado sueño, el de hacer de Guinea Ecuatorial parte de su pré-carré de África Central al lado de Gabón, Congo, Camerún, Centroáfrica y Chad. El descubrimiento en Guinea Ecuatorial a finales de los años ochenta de importantes yacimientos de petróleo y de gas acaba convirtiendo al país en un objeto de codicia por parte de las grandes potencias occidentales y conforta a París en su voluntad de "arrebatarle" a España su ex colonia. Finalmente en 1989, por decisión exclusiva del presidente Teodoro Obiang, Guinea Ecuatorial se hace miembro de la Francofonía. Se trata, luego de haber adherido al país en la zona monetaria del franco C.F.A. (Comunidad Financiera de África) - una moneda controlada desde París y utilizada en las antiguas colonias francesas del África subsahariana en 1985-, de integrarse mejor económica y culturalmente en el espacio regional francófono constituido

${ }_{18}$ En su libro, Muakuku Rondo Igambo plantea el crucial problema de la gobernabilidad en un estado multiétnico como son los países africanos y lo aplica a Guinea Ecuatorial, planteando la posibilidad de que un pequeño estado, con cinco o seis grupos étnicos muy diferentes en cuanto a concepciones culturales, en cuanto a número y en cuanto peso político, pueda ser gobernado en paz y en armonía.

19 Una de las resoluciones del Congreso proponía la creación en Guinea Ecuatorial de una Academia de la Lengua Española. Pero dicha resolución chocaba con los intereses franceses y su proyecto de incorporar la antigua colonia española a la Francofonía.

Revista Iberoamericana, Vol. LXXX, Núms. 248-249, Julio-Diciembre 2014, 883-898 ISSN 0034-9631 (Impreso) 
exclusivamente por países francófonos de antiguas colonias francesas. ${ }^{20}$ Como muchos intelectuales guineanos, Justo Bolekia en su ensayo La francofonía. El nuevo rostro del colonialismo en África piensa que la presencia de su país en esta organización sólo "obedece a razones políticas y económicas" -muy lejos de aspectos culturales como afirman las autoridades guineanas, todas ellas favorecidas por el imperialismo francés sobre el continente africano. Ya en 1997, en una columna titulada "Guinea francófona" publicada en la revista misionera Mundo Negro, Donato Ndongo observaba que París se había convertido en el mentor de la política guineana, pues "mientras España estaba replegada sobre sí misma con la euforia del triunfo socialista en los primeros años 80 , los socialistas franceses lograban que Obiang entrara en la zona del franco y pasaban a controlar todos los resortes económicos y estratégicos del pequeño enclave hispanófono en África" (Ndongo, "Guinea francófona" 9).

Críticos como Sosthène Onomo, cuya opinión compartimos en gran medida, se suma a los anteriormente mencionados y se muestra escéptico en cuanto a la integración cultural de Guinea Ecuatorial en un entorno dominado por el francés como lengua principal hablada en todos los demás países del África Central. El investigador camerunés observa que a pesar de los esfuerzos desplegados desde París para forzar la integración de Guinea en el ámbito francófono de África Central, el país de Teodoro Obiang parece todavía sufrir de su pasado colonial hispano, puesto que la herencia colonial española resulta difícil de superar para los guineanos: la cultura, un cierto complejo de inferioridad respecto a sus vecinos de países francófonos, un sentimiento de exclusión, una inseguridad social, la opresión, el analfabetismo, una permanente necesidad de dependencia, etc., son tantos escollos que no permiten que el guineano se sienta en el mismo nivel que sus vecinos de Gabón, Congo, Camerún, Centroáfrica o Chad. Sin embargo, conviene matizar que el "boom" petrolero de los años noventas ha propulsado a Guinea Ecuatorial en la cima de la economía de la sub-región, llegando a controlar el país más de la mitad de los ingresos del B.E.A.C. (Banco de los Estados de África Central). Lo cual constituye un motivo de orgullo para los guineanos frente a sus vecinos de las antiguas colonias francesas.

\section{REPLIEGUE IDENTITARIO}

"Escuchadme bien habitantes de acá / Comprar cuerdas en Madrid no es progreso / Solamente haremos algo de peso / Sacando fibras del buen abacá" (Ávila Laurel, Poemas

${ }^{20}$ Sobre este tema, además del mencionado libro de Justo Bolekia, se puede consultar los siguientes estudios: Xavier Deniau, La francophonie; Sosthène Onomo, "Guinée Equatoriale et intégration sous régionale: le rôle de la France. Quelques points de repères historiques"; Gisèle Avome, "La francofonía en Guinea Ecuatorial"; Chistiane Albert, Francophonie et identités culturelles.

Revista Iberoamericana, Vol. LXXX, Núms. 248-249, Julio-Diciembre 2014, 883-898 
21). Esos versos sacados de Poemas (1994) bien pueden leerse como el distanciamiento, la demarcación o la discrepancia de Juan Tomás Ávila Laurel y de la nueva generación de los escritores guineanos con sus mayores respecto al tema crucial del exilio. Los escritores guineanos de la nueva generación, catalogados por José Fernando Siale como "neoindependentistas", ${ }_{21}$ también quieren ver su labor creativa como una tarea de revelación de la realidad política y social de su entorno. Michael Ugarte, cuyas ideas compartimos, habla de ellos como "exiles stay at home" y ve en sus dificultades "the tribulations and dangers of writing against the dictatorial regime while living within that regime and a sense of estrangement from within" (xiii); es decir, una verdadera olla a presión. A diferencia de sus mayores de la generación de "los años del silencio", ellos no conocieron, por lo menos de forma directa, los avatares de la dictadura de Macías, ni el exilio como consecuencia de la tiranía. Cuando estalla la tragedia unos meses después de la independencia, José Fernando Siale, el mayor en este grupo, apenas tiene ocho años, Juan Tomás Ávila Laurel tres, Maximiliano Nkogo, César Mba Abogo y Guillermina Mekuy ni habían nacido. La dictadura de Obiang empieza cuando José Fernando Siale tiene dieciocho años, Juan Tomás Ávila Laurel trece, Maximiliano Nkogo siete, César Mba acababa de nacer y Guillermina Mekuy ni había nacido. Esta nueva generación de escritores guineanos vive una especie de exilio interior, cuya razón principal es el desinterés manifestado por las autoridades guineanas hacia su cultura, hacia su literatura. José Fernando Siale confesaba al respecto que las obras de los autores nacionales no estaban "incluidas en los planes de enseñanza del sistema educativo nacional", ${ }^{22}$ lo cual significa que los escritores guineanos ni se leen, ni se estudian dentro de su propio país. En un Congreso organizado en Madrid en noviembre de 2008 sobre la literatura africana escrita en español, Juan Tomás Ávila Laurel afirmaba: "es imposible vivir de la escritura en un país como el mío. Ser escritor en Guinea es como ser alpinista en el Sahara", refiriéndose a las numerosas dificultades con las que se enfrentan a diario los escritores que viven dentro de Guinea. Un personaje de Nambula de Maximiliano Nkogo, en una alusión metafórica a Guinea Ecuatorial, reconoce que el pueblo de "Nambula se ha convertido en un país estéril, que ni produce talentos ni favorece la creatividad, donde reina la mediocridad y la barbarie" (37). Desde luego, los escritores de este grupo quieren utilizar su pluma para revelar la realidad guineana, pero ya no desde la perspectiva de desvelar los grandes secretos políticos, sino de escribir sobre los problemas cotidianos que ellos comparten directamente con los guineanos. Su escritura trata de combatir el triunfalismo y la hipocresía imperantes. Sus paisajes, sus

${ }^{21}$ Compartimos esta expresión que traduce la voluntad de independizarse de sus mayores tanto temática como formalmente.

22 José Fernando Siale hizo esta declaración en una Conferencia que pronunció el 30 de marzo de 2009 en el Black Culture Center en la Universidad de Missouri, Columbia.

Revista Iberoamericana, Vol. LXXX, Núms. 248-249, Julio-Diciembre 2014, 883-898 
personajes y sus historias remiten a un universo conocido de todos sus compatriotas; la verosimilitud es la clave de esta literatura destinada a enfrentar al público guineano con su realidad más próxima. Se trata de poner a la luz pública los problemas cruciales de la Guinea actual que son el mal gobierno, la violación de los derechos humanos y de las libertades individuales, los abusos de todos tipos, la corrupción, el nepotismo, las desgracias relacionadas con la explotación petrolera, etc.

En total, se trata de asumir la identidad del guineano de a pie, es decir, el guineano de los suburbios abandonados de Malabo, de Bata o de Niefang, el guineano de las carreteras polvorientas de Rebola, Luba o Basakato, el guineano de las playas abandonadas de Annobón o de Corisco. En una reafirmación de la función social de la literatura, un narrador de Maximiliano Nkogo señala que "la literatura suele ser el termómetro que mide los altibajos espacio-temporales de un determinado grupo social" (Nkogo, Adjá-Adjá 25). Una definición que identifica a los escritores guineanos con las preocupaciones de los literatos del conocido "Boom" de la Nueva Novela hispanoamericana. Mario Vargas Llosa había lanzado el grito al aire con su ya famoso "la literatura es fuego" en los años setentas; el escritor peruano entendía el papel del escritor como un despertador o agitador de conciencias, un gendarme de la sociedad con el único propósito de estimular los cambios sociales y la mejora de las condiciones de vida de los miembros de cada grupo social.

\section{BiBLIOGRAFÍA}

Albert, Chistiane. Francophonie et identités culturelles. París: Karthala, 1999.

Ávila Laurel, Juan Tomás. Poemas. Malabo: Centro Cultural Hispano-Guineano, 1994. Guinea Ecuatorial. Visceras. Valencia: Institució Alfons el Magnànim, 2006.

Avome, Gisèle. "La francofonía en Guinea Ecuatorial”. Estudios Africanos XIV/25-26.

Madrid: Asociación Española de Africanistas, 1999: 109-23.

Balboa Boneke, Juan. ¿Dónde estás Guinea?. Palma de Mallorca: Cort, 1978. y Nguema Esono, Fermín. La transición de Guinea Ecuatorial. Historia de un

fracaso. Madrid: Labrys, 1996.

Bolekia Boleká, Justo. Aproximación a la historia de Guinea Ecuatorial. Salamanca: Amarú, 2003.

La francofonía. El nuevo rostro del colonialismo en África. Salamanca: Amarú Ediciones, 2005.

"Rasgos esenciales de la poesía guineoecuatoriana". Palabras 1 (2009): 43-60. Carrasco González, Antonio. La novela colonial hispanoafricana. Madrid: SIAL, 2000. Deniau, Xavier. La francophonie. París: PUF, 2003.

Djibril, M. “Guinea Ecuatorial, el gulag africano”. Mundo Negro XIX/204 (oct. 1978): 31-32.

Revista Iberoamericana, Vol. LXXX, Núms. 248-249, Julio-Diciembre 2014, 883-898 
Evita, Leoncio. Cuando los combes luchaban. Novela de costumbres de la antigua Guinea Española. 1953. Malabo: Centro Cultural Hispano-Guineano, 1996.

Fernández, Rafael. Guinea, materia reservada. Madrid: Sedmay, 1976.

González Echegaray, Carlos. "Prólogo a la primera edición". Cuando los combes luchaban. Novela de costumbres de la antigua Guinea Española. Madrid: Consejo Superior de Investigaciones Científicas-Instituto de Estudios Africanos, 1953. 11-12.

"Prólogo a la segunda edición". Cuando los combes luchaban. Novela de costumbres de la antigua Guinea Española. Madrid: Consejo Superior de Investigaciones Científicas-Instituto de Estudios Africanos, 1953. 13-18.

Jones Mathema, Daniel. Una lanza por el boabí. Barcelona: Casals, 1962.

López Rodríguez, Marta Sofía. "Escritoras guineanas: breve crónica de un cuarto de siglo". Palabras 1 (2009): 73-96.

Mbomio Bacheng, Joaquín. "El jeringazo de Ciriaco Bokesa en Los poderes de la tempestad dio de lleno". El Patio 65 (julio-agosto 1999): 47-49.

El párroco de Niefang. Malabo: Centro Cultural Hispano-Guineano, 1996.

Muakuku Rondo Igambo, Fernando. Conflictos étnicos y gobernabilidad. Guinea Ecuatorial. Madrid: Carena, 2006.

Ndongo Bidyogo, Donato. Antología de la literatura guineana. Madrid: Editora Nacional, 1984.

"Guinea francófona”. Mundo Negro. Feb. 1997: 9.

Historia y tragedia de Guinea Ecuatorial. Madrid: Cambio 16, 1977.

Los poderes de la tempestad. Madrid: Morandi, 1997.

y Mbare Ngom. Literatura de Guinea Ecuatorial (Antología). Madrid: SIAL, 2000.

Nerín, Gustau. "Entre la realidad y la ficción. Guinea Ecuatorial en la literatura". Misceláneas guineoecuatorianas. Madrid: Tiempos Próximos, 2002. 121-36.

Ngom, Mbare. "La autobiografía como plataforma de denuncia en Los poderes de la tempestad de Donato Ndongo Bidyogo". Afro-Hispanic Review 19/1 (2000): 66-71.

"La literatura africana de expresión castellana: la creación literaria en Guinea Ecuatorial". Hispania 76 (sept. 1993): 410-18.

"Literatura africana de expresión española". Cuadernos Centro de Estudios Africanos 3 (2003): 111-35.

Nkogo Esono, Maximiliano. Adjá-Adjá y otros relatos. Malabo: Centro Cultural Hispano-Guineano, 1994.

Nambula. Madrid: Morandi, 2006.

Nkogo Ondó, Eugenio. El problema humano. Madrid: Celarayn, 1985.

Nsue Angüe, María. Ekomo. Madrid: U.N.E.D., 1985.

Onomo-Abena, Sosthène. "Guinée Equatoriale et intégration sous régionale: le rôle de la

France. Quelques points de repères historiques”. Dynamiques d'intégration régionale en Afrique Centrale. Yaoundé: Presses Universitaires de Yaoundé, 2001. 189-98.

Revista Iberoamericana, Vol. LXXX, Núms. 248-249, Julio-Diciembre 2014, 883-898 
y Joseph-Désiré Otabela Mewolo. Literatura emergente en español: literatura de Guinea Ecuatorial. Madrid: Ediciones del Orto, 2004.

Otabela, Joseph-Désiré y Sosthène Onomo-Abena. Entre estética y compromiso. La obra de Donato Ndongo-Bidyogo. Madrid: U.N.E.D., 2008.

Sampedro, Benita. "Estudio introductorio". Guinea Ecuatorial. Visceras. Juan-Tomás Ávila Laurel. Valencia: Institución Alfonso el Magnánimo, 2006. 7-20.

Siale Djangany, José Fernando. "Escritores guineanos y expresión literaria”. Conferencia pronunciada en la Universidad de Missouri, Columbia. 30 marzo 2009. Ponencia. Ugarte, Michael. Africans in Europe. The Culture of Exile and Emigration from Equatorial Guinea to Spain. Chicago: U of Illinois P, 2010.

Wa Thiong'o, Ngugi. “The Culture of Silence and Fear”. South (mayo 1984): 37-38. Zamora Loboch, Francisco. Memoria de laberintos. Madrid: Casa de África, 1999.

Zielina Limonta, María. "Ekomo: representación del pensamiento mítico, la magia y la psicología de un pueblo 'fang"”. Afro-Hispanic Review 19/1 (2000): 93-101. 